\title{
HAPTIC RECOGNITION OF FAMILIAR OBJECTS: EXAMINING LATERALIZATION OF SPECIFICITY EFFECTS ${ }^{1}$
}

\author{
JULIO GONZÁLEZ-ALVAREZ AND MARÍA-ÁNGELES PALOMAR-GARCÍA
}

\author{
Universitat Jaume I, Castellón, Spain
}

\begin{abstract}
Summary.-Previous research has found evidence in favor of two subsystems underlying object recognition: an abstract-category subsystem that mainly works in the left hemisphere ( $\mathrm{LH}$ ) and a specific-exemplar subsystem that mainly works in the right hemisphere (RH). This asymmetry has been observed in both the visual and auditory domains by means of long-term repetition priming experiments. This study explored whether this asymmetrical pattern extends to the haptic domain through an experiment in which 30 right-handed participants ( 24 women) ages 18 to 38 years could identify familiar objects with a single hand. The procedure included two blocks of trials, the study (presentation of primes) and the test phase (presentation of targets), separated by a short distractor task. Of interest was if repetition of the same exemplar object (e.g., the same cigarette lighter) produced more priming than repetition of a different exemplar of the same object category (e.g., a different cigarette lighter), and, crucially, if this hypothetical same-exemplar advantage (specificity) was larger when objects were identified with the left hand $(\mathrm{RH})$. An ANOVA was performed on RTs with priming type (same-exemplar primed, different-exemplar primed and unprimed) and hand (left, right) as within-participants factors. Results showed a main effect of priming type due to a same-exemplar advantage (shorter RTs) both for the left and the right hand, but a non-significant interaction between specificity effects and hands.
\end{abstract}

A number of studies have produced evidence suggesting there are two dissociable subsystems, or processing styles, in both the visual and the auditory domains. In visual perception, Marsolek and other authors have proposed two parallel subsystems processing words and objects: an Abstract-Category subsystem that functions more efficiently in the left hemisphere (LH) and is less sensitive to specific physical properties of stimuli, and a Specific-Exemplar subsystem that functions more efficiently in the right hemisphere $(\mathrm{RH})$ and is more sensitive to specific properties of stimuli (Marsolek, 1999, 2003; Marsolek \& Burgund, 2008). The main support of this hypothesis comes from research using long-term repetition-priming experiments. Repetition priming can be defined as any facilitation in the processing of a stimulus that has been presented previously (Bowers, 1999). In the typical procedure, a first block of trials (study phase) is presented to the participants to process a set of stimuli. After a short distractor task, a second block of trials (test phase) is presented in-

${ }^{1}$ Address correspondence to Julio González-Alvarez, Ph.D., Department of Basic and Clinical Psychology and Psychobiology, Universitat Jaume I, Av. Vicent Sos Baynat s/n, 12071 Castellón de la Plana, Spain or e-mail (gonzalez@psb.uji.es). 
cluding some of the stimuli presented in the first block. Typically, repeated stimuli are processed faster than new stimuli. However, if the first (prime) and the second (target) trials including the same stimulus mismatch on some property (e.g., letter case in written words, different voice in spoken words, different exemplars in object recognition), the priming effect may be reduced. This reduction in priming in the different-exemplar condition (or, conversely, a relative greater priming in the same-exemplar condition) is known as Specificity (or a Specificity Effect). Research conducted by Marsolek and colleagues obtained asymmetric patterns of specificity: weak or no specificity in the LH and more specificity in the RH. Evidence of this lateralization has been observed in tasks involving identification of written words (Marsolek, Schacter, \& Nicholas, 1996; Marsolek, 2004; but see Koivisto, 1995), perception of pseudowords (Burgund \& Marsolek, 1997), letter-like forms (Marsolek, 1995), recognition of familiar objects (Marsolek, 1999; Burgund \& Marsolek, 2000) and novel objects (Marsolek \& Burgund, 2008).

In Marsolek's (1999) study, participants were required to recognize objects (e.g., a piano) presented in either the left visual field ( $\mathrm{RH})$ or the right visual field (LH), after a first block of trials in which stimuli were centrally presented. Some of the objects were repetitions of the same exemplar previously presented, whereas others were a different exemplar from the same category (e.g., a different piano). A similar priming was observed when the same or different exemplars were presented to the LH, but priming decreased (specificity) when the different exemplars were presented to the $\mathrm{RH}$.

In the auditory domain, a similar asymmetric pattern of specificity has been found in the identification of spoken words (González \& McLennan, 2007), environmental sounds (González \& McLennan, 2009), and talkers (González, Cervera-Crespo, \& McLennan, 2010). In the 2009 study, the authors obtained specificity effects by means of a long-term priming paradigm when sounds were presented to the left ear $(\mathrm{RH})$, but not when presented to the right ear ( $\mathrm{LH})$. Given the similarity of results across the visual and auditory domains, González and McLennan (2009) suggested that the asymmetrical pattern of specificity effects of priming might be not restricted to a particular modality, but might be a general property of the human perceptual-processing system. They pointed out that research could extend to the three remaining sensory modalities (touch, taste, and smell). For example, it would be an interesting question whether specificity in tactile recognition is greater when objects are handled with the left hand (right hemisphere) than when they are handled with the right hand (left hemisphere). The present work addressed this question examining lateralization of priming specificity during haptic recognition of familiar objects. 
Previous research has studied haptic priming (Ballesteros, Reales, \& Manga, 1999a, 1999b; Ballesteros \& Reales, 2004; Ballesteros, Reales, Mayas, \& Heller, 2008; Craddock \& Lawson, 2008, 2009a, 2009b; Tomlinson, Davis, Morgan, \& Bracewell, 2011; Sebastián \& Ballesteros, 2012; Pesquita, Brennan, Enns, \& Soto-Faraco, 2013), but no work has examined lateralization of specificity effects (same vs different exemplars) in haptic processing. A long-term repetition-priming experiment was carried out in which participants had to identify familiar objects with a single hand and observed if specificity was hemispherically asymmetrical. More specifically:

Hypothesis 1. Repetition of the same object exemplar will produce more priming (shorter RTs) than the repetition of a different exemplar belonging to the same category.

Hypothesis 2. Specificity effects will be significantly larger when objects are recognized by means of the left hand (RH) than when the same objects are recognized by means of the right hand (LH).

\section{METHOD}

\section{Participants}

Thirty participants (24 women) were recruited from the Universitat Jaume I of Castellón (Spain) and received partial credit for a course requirement. Ages ranged from 18 to 38 years $(M=20.2, S D=4.9)$ and all participants were right-handed (scoring +80 or above on the Edinburgh Handedness Inventory; Oldfield, 1971) and native speakers of Spanish with normal hearing. The experimental protocol was approved by Universitat Jaume I's ethics committee.

\section{Materials}

The experimental stimuli consisted of two exemplars of 30 categories of familiar objects (see Appendix). Objects were typical examples of manmade, nameable and well-known artifacts from a wide range of categories (similar to those used by Ballesteros, et al., 2008; Craddock \& Lawson, 2009a, 2009b; Sebastián \& Ballesteros, 2012). The objects had a size that allowed haptic exploration with a single hand and they did not emit any special noise ${ }^{2}$ or odor that would allow them to be recognized (Ballesteros, et al., 2008; Sebastián \& Ballesteros, 2012). Six additional familiar objects were included only for practice trials. Each member (exemplar) of each pair of objects was randomly assigned to one of two stimulus sets; stimuli from one of the sets were used as targets and stimuli from the other set were used as primes in the different-exemplar condition.

${ }^{2} \mathrm{~A}$ piece of paper was inserted into the whistles to avoid any sound during the hand exploration. 


\section{Design}

The experiment consisted of a typical long-term priming paradigm (Marsolek, 1999; González \& McLennan, 2007, 2009) and included two blocks of trials, the study (presentation of primes) and the test phase (presentation of targets), separated by a distracter task of 4-5 min. (fulfilling the Edinburgh Handedness Inventory and arithmetic).

The design was a combination of three levels of priming (same-exemplar primed, different-exemplar primed, and unprimed or control) and two levels of hand of stimulus presentation/exploration (left, right), resulting in six within-participants conditions. In order to ensure that each target was assigned to every possible condition, six stimulus lists were created and each participant was randomly assigned to one of them. No participant was presented with more than one version of an object category within a block.

In the study phase, 20 stimuli were presented in random order: five same-exemplar primes to the left hand, five same-exemplar primes to the right hand, five different-exemplar primes to the left hand, and five different-exemplar primes to the right hand. In the test phase, 30 stimuli were also presented in random order: 10 same-exemplar targets (i.e., the same item as in the study phase), 10 different-exemplar targets (i.e., a different item from the same object category as in the study phase), and 10 control or non-repeated targets; in each of the six conditions, five targets were presented to the left hand and five to the right hand in pseudorandom order (no more than two consecutive trials using the same hand). There was correspondence between hands across the phases: if a stimulus was presented to the left hand during the study phase, the same item (or object category) was also presented to the left hand during the test phase, and likewise for the right hand. Stimuli of each block were preceded by three practice trials.

\section{Procedure}

The experiment was individually administered in a quiet room. At the beginning of the session, participants were given a list of names of the objects that would appear in the experiment and were asked to read them aloud (Craddock \& Lawson, 2009a, 2009b). They were told that they were required to recognize and name the objects in the list by touch, picking them up with a single hand in each trial. Then participants were seated at a table wearing a special mask that did not allow them to see anything. The procedure was similar to that of Ballesteros, et al.'s (2008) Experiment 2 and Craddock and Lawson's (2008, 2009a, 2009b) experiments. Two flat plates of $21 \mathrm{~cm}$ diameter and $1.7 \mathrm{~cm}$ height that had been fixed to the table and separated $5 \mathrm{~cm}$ apart served as presentation platforms. Felt carpet 
was attached to the bottom of each platform to muffle sounds made by placing the objects and to prevent the rotation of the objects. Two pieces of masking tape on the table indicated the starting positions where participants had to place their hands at the beginning of each trial.

Before each trial, the assistant quietly placed an object on one of the plates following the indications of the stimulus list. All the stimuli were presented in the center of the platform. Elongated objects were placed in a vertical orientation in the two-dimensional plane and bilaterally asymmetrical objects were placed in the appropriate orientation for normal use (e.g., a comb was placed in vertical orientation with teeth facing right for the left exploration hand, and teeth facing left for the right exploration hand). Once the object was placed, the assistant said the hand (left vs right) that should be used in the next trial. Approximately 2 sec. later, the assistant said "Ya" (go) to indicate that the participant could pick up the object. Participants were instructed to identify the object both quickly and accurately. A timer measuring to hundredths of a second was started the instant the hand touched the object for the first time, and the timer was stopped when the participant started to vocalize the name of the object.

\section{RESULTS}

Participants recognized objects correctly on $98.8 \%$ of all trials. The dependent variable was the reaction time (RT) corresponding to correct responses in the test phase. As the metric for each participant, the median ${ }^{3}$ rather than mean RTs were used, since the median is less affected by the distributional skew often observed in distributions of RTs in haptic processing tasks (Craddock \& Lawson, 2008, 2009a, 2009b). Table 1 shows the means of median response times when naming objects presented at left or right hand under the three priming conditions; in Table 1, number of errors are also presented. A two-way repeated-measures ANOVA was conducted on RTs with priming type (same-exemplar primed, different-exemplar primed, and unprimed or control) and hand (left, right) as within-participants factors. Separate analyses were performed with participants $\left(\mathrm{F}_{1}\right)$ and items $\left(\mathrm{F}_{2}\right)$ as the random variables. ${ }^{4}$

There was a significant main effect of priming type in both analyses. No other significant effects were obtained; i.e., no main effect of hand of presentation and, crucially, no interaction effect of priming type $\times$ hand of presentation. The main effect was due to differences in reaction times (RT) between all priming conditions (Table 2). According to the planned com-

${ }^{3}$ The general pattern of results was not different using mean RTs once outlying values were eliminated.

${ }^{4}$ Given the low rate of errors [11 errors from a total of 900 observations ( 30 participants $\times 30$ targets)], it was not appropriate to perform an ANOVA on the number of errors. 
TABLE 1

Means of Median Reaction Times (RTs) in Msec. With SD For Correct Responses and Number of Errors (and Omissions) For Each Experimental Condition During Haptic IDENTIFICATION OF FAMILIAR OBJECTS

\begin{tabular}{|c|c|c|c|c|c|c|}
\hline & \multicolumn{2}{|c|}{ Same-exemplar Primed } & \multicolumn{2}{|c|}{ Different-exemplar Primed } & \multicolumn{2}{|c|}{ Unprimed (Control) } \\
\hline & $M$ & $S D$ & $M$ & $S D$ & $M$ & $S D$ \\
\hline \multicolumn{7}{|l|}{ RT (msec.) } \\
\hline Left hand & 1669 & 466 & 1984 & 533 & 2438 & 655 \\
\hline Right hand & 1691 & 270 & 2040 & 512 & 2373 & 907 \\
\hline Errors & \multicolumn{2}{|c|}{ Number } & \multicolumn{2}{|c|}{ Number } & \multicolumn{2}{|c|}{ Number } \\
\hline Left hand & \multicolumn{2}{|c|}{0} & \multicolumn{2}{|c|}{0} & \multicolumn{2}{|c|}{5} \\
\hline Right hand & \multicolumn{2}{|c|}{1} & \multicolumn{2}{|c|}{1} & \multicolumn{2}{|c|}{4} \\
\hline
\end{tabular}

parisons, the RT difference between the same-exemplar vs different-exemplar conditions was significant when the target stimuli were presented to the left hand and also when presented to the right hand. Likewise, the difference between the different-exemplar priming vs unprimed conditions was significant when the target stimuli were presented to the left hand and when presented to the right hand (Table 2).

Conducting an ANOVA only with same- vs different-exemplar priming (specificity) $\times$ hand of presentation, there was a main effect of specificity (participants: $F_{1,29}=48.46, p<.0001, \mathrm{MSE}=68309.37, \eta_{\mathrm{p}}^{2}=0.63$; items: $\left.F_{1,29}=15.12, p=.001, \mathrm{MSE}=171558.83, \eta_{\mathrm{p}}^{2}=0.34\right)$, but not a hand effect $(F \mathrm{~s}<1)$ and, crucially, not an interaction effect of specificity $\times$ hand of presentation $(F \mathbf{s}<1)$. Specificity mean (same vs different condition RT) for the left hand was $-315 \mathrm{msec}$. $(95 \% \mathrm{CI}=-504,-126)$ and for the right hand was $-349 \mathrm{msec}$. $(95 \% C I=-536,-163)$. The difference between Specificity Effects across hands (left vs right) was $-34 \mathrm{msec}$. $(95 \% \mathrm{CI}=-285,354)$. These results supported Hypothesis 1 , that repetition of the same object exemplar produced more priming (shorter RTs) than the repetition of a different exemplar belonging to the same category; they did not support Hypothesis 2, that specificity effects are significantly larger when objects are recognized by means of the left hand $(\mathrm{RH})$ than when the same objects are recognized by means of the right hand (LH).

\section{DisCUSSION}

Previous evidence has shown asymmetry of priming specificity in visual perception, and recently also in the auditory domain. The present work parallels González and McLennan's (2009) study carried out with environmental sounds, in which changing a sound exemplar had a greater effect when the left ear (RH) was used to identify the sound. The main question examined in the present research was whether specificity effects 
TABLE 2

Two-way Repeated-measures Analyses of Variance (ANOVAs) on Reaction Times With Priming Type (Same-eXemplar Primed, Different-eXemplar Primed, and Control) and Hand (left, Right) as Within-participants Factors. Separate Analyses For Participants and Items. For Each Effect Size $\left(\eta_{\mathrm{p}}^{2}\right)$, a 95\% Confidence Interval was Calculated Following SMithson (2003)

\begin{tabular}{|c|c|c|c|c|c|c|c|}
\hline \multirow[b]{2}{*}{ Source } & \multicolumn{5}{|c|}{ Main Analyses } & \multicolumn{2}{|c|}{ Planned Comparisons } \\
\hline & $d f$ & MSE & $F$ & $p$ & $\eta_{\mathrm{p}}^{2}$ & $\begin{array}{c}\text { Same vs } \\
\text { Different } \\
\text { Exemplars }\end{array}$ & $\begin{array}{l}\text { Different vs } \\
\text { Unprimed } \\
\text { Exemplars }\end{array}$ \\
\hline \multicolumn{8}{|l|}{ Participants } \\
\hline \multirow[t]{2}{*}{$\begin{array}{l}\text { Priming type } \\
\quad(\mathrm{P})\end{array}$} & 2,58 & 192393.76 & 41.16 & $<.0001$ & $\begin{array}{c}0.59 \\
(0.40,0.69)\end{array}$ & $\begin{array}{l}\text { Left hand, } \\
\qquad \eta_{p}^{2}=0.29 \\
(0.05,0.50)\end{array}$ & $\begin{array}{l}\text { Left hand, } \\
\qquad \eta_{p}^{2}=0.34 \\
(0.08,0.54)\end{array}$ \\
\hline & & & & & & $\begin{array}{l}\text { Right hand, } \\
\qquad \eta_{p}^{2}=0.34 \\
(0.08,0.54)\end{array}$ & $\begin{array}{l}\text { Right hand, } \\
\eta_{p}^{2}=0.13 \\
(0.00,0.35)\end{array}$ \\
\hline Hand (H) & 1,29 & 286372.05 & $<1$ & .959 & $\begin{array}{c}0.001 \\
(0.00,0.07)\end{array}$ & & \\
\hline $\mathrm{P} \times \mathrm{H}$ & 2,58 & 278992.09 & $<1$ & .812 & $\begin{array}{c}0.01 \\
(0.00,0.07)\end{array}$ & & \\
\hline \multicolumn{8}{|l|}{ Items } \\
\hline \multirow[t]{2}{*}{$\begin{array}{l}\text { Priming type } \\
(\mathrm{P})\end{array}$} & 2,58 & 385836.75 & 30.25 & $<.0001$ & $\begin{array}{c}0.51 \\
(0.31,0.62)\end{array}$ & $\begin{array}{l}\text { Left hand, } \\
\qquad \eta_{\mathrm{p}}^{2}=0.25 \\
\quad(0.03,0.46)\end{array}$ & $\begin{array}{l}\text { Left hand, } \\
\qquad \eta_{p}^{2}=0.39 \\
(0.12,0.58)\end{array}$ \\
\hline & & & & & & $\begin{array}{l}\text { Right hand, } \\
\quad \eta_{p}^{2}=0.23 \\
(0.02,0.45)\end{array}$ & $\begin{array}{l}\text { Right hand, } \\
\eta_{p}^{2}=0.22 \\
(0.02,0.44)\end{array}$ \\
\hline Hand (H) & 1,29 & 136088.43 & 2.63 & .12 & $\begin{array}{c}0.08 \\
(0.00,0.30)\end{array}$ & & \\
\hline $\mathrm{P} \times \mathrm{H}$ & 2,58 & 233774.54 & 2.02 & .14 & $\begin{array}{c}0.07 \\
(0.00,0.19)\end{array}$ & & \\
\hline
\end{tabular}

are stronger when objects are touched and explored with the left hand (RH) than when the same objects are touched and explored with the right hand $(\mathrm{LH})$. The data showed that the procedure was sensitive to the presence of specific effects and RTs were significantly shorter (for both hands) when participants identified familiar objects after the repetition (studytest) of an identical exemplar (the same cigarette lighter) than after the repetition of a different exemplar object belonging to the same category (a different cigarette lighter), but they did not show a difference of specific effects across the two hands.

The absence of a significant difference in specificity between both hands might be due to: (1) an actual lack of hemispherical lateralization of specificity effects in the task of recognizing familiar objects under the 
methodological conditions of the current study, or (2) the experiment was not sensitive enough to detect effects of hemispheric lateralization or an interaction between hemispheres and specificity. It is important to note that a possible specificity lateralization presumably would be much smaller than specificity effects. A difference of -34 msec. was observed between left vs right hands in the time necessary to recognize the target objects, but the 95\% confidence interval of that difference ranged widely from $-285 \mathrm{msec}$. to $+354 \mathrm{msec}$. It can not be ruled out that further research with higher statistical power could find some significant lateralization in haptic recognition of familiar objects.

On the basis of the current study, any extrapolation to the haptic domain of the hemispheric lateralization of priming specificity found in the visual and the auditory domains would be premature. If future research demonstrated that this is the case, a plausible explanation could be that vision and audition share some properties that they do not share with touch or haptic processing. Vision and audition are "distal" senses that intervene in the perception of objects distant from the boundaries of our skin. People typically recognize and categorize objects in the environment by means of vision and (secondarily) audition. In contrast, touch is a "proximal" sense that requires contact with the body. Usually when one comes in contact with an object—or more specifically, when an object is grasped - the object has been previously identified by the "distal" senses. Unless we restrict vision and/or audition, haptic processing scarcely intervenes in object recognition in natural situations. This hypothesis could be tested directly by using congenitally blind participants whose "natural" way of object recognition is haptic.

Nevertheless, further tests of asymmetry of specificity in haptic processing are needed with higher statistical power and including additional variables associated with tactual perception (e.g., kinds of stimuli, types of stimuli exploration, active vs passive touch; for a review, see Lederman \& Klatzky, 2009, and Fernandes \& Albuquerque, 2012).

\section{REFERENCES}

Ballesteros, S., \& Reales, J. M. (2004) Intact haptic priming in normal aging and Alzheimer's disease: evidence for dissociable memory systems. Neuropsychologia, 42(8), 1063-1070. DOI: 10.1016/j.neuropsychologia.2003.12.008

Ballesteros, S., Reales, J. M., \& Manga, D. (1999a) Implicit and explicit memory for familiar and novel objects presented to touch. Psicothema, 11, 785-800.

Ballesteros, S., Reales, J. M., \& Manga, D. (1999b) Memoria implícita y memoria explícita intramodal e intermodal: influencia de las modalidades elegidas y del tipo de estímulos [Within-modal and cross-modal implicit and explicit memory: influence of modalities and the stimulus type]. Psicothema, 11, 831-851. 
Ballesteros, S., Reales, J. M., Mayas, J., \& Heller, M. A. (2008) Selective attention modulates visual and haptic repetition priming: effects in aging and Alzheimer's disease. Experimental Brain Research, 189(4), 473-483. DOI: 10.1007/ s00221-008-1441-6

BowERS, J. S. (1999) Priming is not all bias: commentary on Ratcliff and McKoon (1997). Psychological Review, 106, 582-596. DOI: 10.1037// 0033-295X.106.3.582

Burgund, E. D., \& MARsoleK, C. J. (1997) Letter-case-specific priming in the right cerebral hemisphere with a form-specific perceptual identification task. Brain $\mathcal{E}$ Cognition, 35, 239-258. DOI: 10.1006/brcg.1997.0940

Burgund, E. D., \& MARsoleK, C. J. (2000) Viewpoint-invariant and viewpoint-dependent object recognition in dissociable neural subsystems. Psychonomic Bulletin $\mathcal{E}$ Review, 7, 480-489. DOI: 10.3758/BF03214360

CRAdDock, M., \& Lawson, R. (2008) Repetition priming and the haptic recognition of familiar and unfamiliar objects. Perception $\mathcal{E}$ Psychophysics, 70(7), 1350-1354. DOI: 10.3758/PP.70.7.1350

CRAdDock, M., \& Lawson, R. (2009a) Do left and right matter for haptic recognition of familiar objects? Perception, 38, 1355-1376. DOI: 10.1068/ p6312

CRaddock, M., \& Lawson, R. (2009b) The effects of size changes on haptic object recognition. Attention, Perception, \& Psychophysics, 71(4), 910-923. DOI: 10.3758/ APP.71.4.910

Fernandes, A. M., \& Albuguerque, P. B. (2012) Tactual perception: a review of experimental variables and procedures. Cognitive Processing, 13, 285-301. DOI: 10.1007/ s10339-012-0443-2

GonzÁlez, J., Cervera-Crespo, T., \& McLennan, C. T. (2010) Hemispheric differences in specificity effects in talker identification. Attention, Perception, \& Psychophysics, 72, 2265-2273. DOI: 10.3758 / APP.72.8.2265

GonZÁlez, J., \& McLennan, C. T. (2007) Hemispheric differences in indexical specificity effects in spoken word recognition. Journal of Experimental Psychology: Human Perception and Performance, 33, 410-424. DOI: 10.1037/0096-1523.33.2.410

GonZÁlez, J., \& McLennan, C. T. (2009) Hemispheric differences in the recognition of environmental sounds. Psychological Science, 20, 887-894. DOI: 10.1111/j.1467-9280. 2009.02379.x

KoIvisto, M. (1995) On functional brain asymmetries in perceptual priming. Brain $\mathcal{E}$ Cognition, 29, 36-53. DOI: 10.1006/ brcg.1995.1266

Lederman, S. J., \& Klatzky, L. R. (2009) Haptic perception: a tutorial. Attention, Perception, \& Psychophysics, 71, 1439-1459. DOI: 10.3758/APP.71.7.1439

MarsoleK, C. J. (1995) Abstract visual-form representations in the left cerebral hemisphere. Journal of Experimental Psychology: Human Perception and Performance, 21, 375-386. DOI: 10.1037/0096-1523.21.2.375

Marsolek, C. J. (1999) Dissociable neural subsystems underlie abstract and specific object recognition. Psychological Science, 10, 111-118. DOI: 10.1111/1467-9280.00117

MARsolek, C. J. (2003) What is priming and why? In J. S. Bowers \& C. J. Marsolek (Eds.), Rethinking implicit memory. London, UK: Oxford Univer. Press. DOI: 10.1093/acpr of:oso / 9780192632326.003 .0003

MARsolek, C. J. (2004) Abstractionist versus exemplar-based theories of visual word priming: a subsystems resolution. The Quarterly Journal of Experimental Psychology: Section A, 57, 1233-1259. DOI: 10.1080/02724980343000747

MarsoleK, C. J., \& Burgund, E. D. (2008) Dissociable neural subsystems underlie visual working memory for abstract categories and specific exemplars. Cognitive, Affective $\mathcal{E}$ Behavioral Neuroscience, 8, 17-24. DOI: 10.3758/CABN.8.1.17 
Marsolek, C. J., Schacter, D. L., \& Nicholas, C. D. (1996) Form-specific visual priming for new associations in the right cerebral hemisphere. Memory \& Cognition, 24, 539-556. DOI: 10.3758 / BF03201082

Oldfield, R. C. (1971) The assessment and analysis of handedness: the Edinburgh inventory. Neuropsychologia, 9, 97-113. DOI: 10.1016/0028-3932(71)90067-4

Pesquita, A., Brennan, A. A., EnNs, J. T., \& Soto-Faraco, S. (2013) Isolating shape from semantics in haptic-visual priming. Experimental Brain Research, 227, 311-322. DOI: 10.1007/ s00221-013-3489-1

Sebastián, M., \& BAllesteros, S. (2012) Effects of normal aging on event-related potentials and oscillatory brain activity during a haptic repetition priming task. NeuroImage, 60, 7-20. DOI: 10.1016/j.neuroimage.2011.11.060

SMithson, M. (2003) Confidence intervals. Thousand Oaks, CA: Sage.

Tomlinson, S. P., Davis, N. J., Morgan, H. M., \& Bracewell, R. M. (2011) Hemispheric specialisation in haptic processing. Neuropsychologia, 49, 2703-2710. DOI: 10.1016/j. neuropsychologia.2011.05.018

Accepted September 10, 2014.

\section{APPENDIX ${ }^{5}$}

Categories of Familiar Objects Used in the Long-term Repetition Priming Experiment Per Category, Two Different Exemplars

\begin{tabular}{lllll}
\hline ashtray & candle & fork & opener & shoehorn \\
ballpoint & clothespin & hair clip & padlock & spoon \\
battery & comb & jar & plug & stapler \\
bottle opener & cork & lantern & ribbon tape & switch \\
bulb & cup & lighter & scissors & whistle \\
cookie-cutter & drain plug & nail brush & screw & zip \\
\hline
\end{tabular}

${ }^{5}$ Note that some two-word names in English correspond to a single-word name in the original Spanish. 